Post-print of: Unzueta, Ugutz et al. "Towards Protein-Based Viral Mimetics for Cancer Therapies" in Trends in Biotechnology

Vol. 33 (2015) , p. 253-258. The final version is available at: https://doi.org/10.1016/j.tibtech.2015.02.007

\title{
OPINION
}

Trends in Biotechnology

\section{Towards Protein-Based Viral Mimetics for Cancer Therapies}

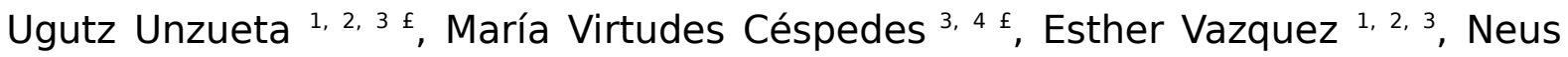
Ferrer-Miralles ${ }^{1,2,3 *}$, Ramón Mangues ${ }^{3,4 *}$ and Antonio Villaverde ${ }^{1,2,3 *}$

${ }^{1}$ Institut de Biotecnologia i de Biomedicina, Universitat Autònoma de Barcelona, Bellaterra, 08193 Barcelona, Spain

2 Departament de Genètica i de Microbiologia, Universitat Autònoma de Barcelona, Bellaterra, 08193 Barcelona, Spain

${ }^{3}$ CIBER de Bioingeniería, Biomateriales y Nanomedicina (CIBER-BBN), Bellaterra, 08193 Barcelona, Spain

${ }^{4}$ Oncogenesis and Antitumor Drug Group, Biomedical Research Institute Sant Pau (IIB-SantPau), Hospital de la Santa Creu i Sant Pau, C/ Sant Antoni Maria Claret, 167, 08025 Barcelona, Spain

${ }^{\text {f Equally contributed }}$

Corresponding authors:

RM Email: rmangues@santpau.cat; phone +34935537918; fax +34935537872

AV Email: antoni.villaverde@uab.cat; phone +34935813086; fax +34935812011 


\section{Abstract}

High resistance and recurrence rates, along with elevated drug clearance, compel the use of maximum tolerated drug doses in cancer therapy, resulting in high-grade toxicities and limited clinical applicability. Promoting active drug accumulation in tumor tissues would minimize such issues and improve therapeutic outcomes. A new class of therapeutic drugs suitable for the task has emerged based on the concept of virus-mimetic nanocarriers, or 'artificial viruses.' Among the spectrum of materials under exploration in nanocarrier research, proteins offer unparalleled structural and functional versatility for designing viruslike molecular vehicles. By exhibiting 'smart' functions and biomimetic traits, protein-based nanocarriers will be a step ahead of the conventional drug-protein conjugates already in the clinics in ensuring efficient delivery of passenger antitumor drugs.

Protein nanoparticles; Drug delivery; Biomaterials; Biomimetics; Protein engineering; 


\section{Drug-based cancer therapies}

Since age is a main factor of risk, the high prevalence of cancer in high-income countries places this disease as a second highest cause of death (around 1 in 4 deaths), after cardiovascular diseases [1]. Despite possible compensatory effects of early detection, the high mortality among cancer patients stresses the limitation of current treatments, many of which are essentially based on surgery and adjuvant chemotherapy [2]. Low molecular weight cytotoxic chemicals, such as 5-Fluorouracil, Cisplatin or Doxorubicin have been developed and used for decades and they represent the current basis of treatment for most cancers [3]. These drugs induce DNA damage, leading to tumor cell death, and are administered at maximum tolerated doses. The resulting high systemic drug levels cause severe toxicities related to DNA damage in highly proliferative healthy tissues (e.g. bone marrow), which worsens patients' quality of life [4]. Poor drug penetration due to abnormal tumor architecture and composition [5], and clearance through hepatic metabolism [6] or renal clearance (with a cut-off around $7 \mathrm{~nm}$; see Glossary) [7] are additional factors that hamper a desired dose reduction to safer, less toxic values.

Renal filtration can be largely minimized by increasing the molecular size of the drug, through conjugation to large molecules such as proteins, which act as carriers. In addition to allowing longer circulation times in the bloodstream, drugprotein conjugation reduces hepatic clearance and increases drug concentration in tumors, compared to free-drug administration. This is because its nanometric size promotes higher nanoconjugate accumulation in tumor tissue because of the enhanced permeability retention (EPR) effect; that is, a form of passive targeting [8;9] (Box 1). In this regard, nab-paclitaxel has been incorporated into treatment regimens for advanced breast, lung or pancreatic cancer. In nab-paclitaxel, the 
bound albumin stabilizes paclitaxel and in effect increases the size of the drug. Because of the many possible benefits of having drugs that are larger than small molecules, nanoparticles (usually ranging from 10 to $100 \mathrm{~nm}$ ) are promising agents in the development of cancer therapies [10]. Most nanoparticles currently used in the clinic exhibit passive targeting (e.g. liposomal doxorubicin, nabpaclitaxel) [11]. In this context, only about $5 \%$ of the injected therapeutic reaches the tumor because the high accumulation $(50-80 \%$ of the dose) of nanoparticles in the mononuclear phagocytic system (MPS) especially in the liver [12-14]. This process could be attenuated through the covalent attachment of polyethylene glycol (PEGylation) to the nanoparticle [15] (Box 1). However, the penetration of nab-paclitaxel into tumors might also benefit from indirect effects. Thus, the albumin component of the nanoparticle may bind to SPARC, a protein secreted by stromal fibroblasts to the tumor extracellular space, or to the gp60 receptor, facilitating nab-paclitaxel endothelial transcytosis [16;17].

\section{Cell targeting in cancer treatments}

A relevant and distinctive property of cancer tissues is that the proteins that drive tumor progression, such as cytokine, hormone or grow factor receptors are differentially overexpressed in cancer stem cells (CSC), as compared to healthy tissues [18]. Such differential expression can enable the molecular tagging of cancer cells for the delivery of next generation drugs. Molecular tags are already implemented in combination with conventional therapies to inhibit signalling from a specific target protein (eg, VEGF, EGFR, HER-2 or B-Raf) [19]. Although less aggressive than in chemotherapy, toxicity can also arise if target activity is inhibited in normal tissues, and resistance can develop through target or pathway mutation (e.g. EGFR amplification) or the activation of alternative or compensatory

pathways 
Learning from these lessons, cell targeting in cancer treatment should be primarily exploited to engineer the biodistribution of conventional, well-known drugs as cargos in long-circulating nanoconjugates, aimed to increase the effective drug concentration in tumor cells. In this regard, if the administered drugs would be introduced in such a way that they only (or preferentially) penetrate tumor cells, doses could be largely reduced and toxicity issues essentially minimized. CSCs are responsible for tumor and metastasis initiation and maintenance and closely associated with aggressiveness. Active drug targeting aimed at eliminating CSCs is then a promising anticancer strategy. This therapeutic approach takes advantage of the differential expression of membrane receptors between CSCs and the bulk of the tumor, mainly composed of differentiated cells [20].

\section{Proteins, virus-like functions and artificial viruses}

In nature, animal viruses, which are nanoscale in size, exhibit exquisite specificity for cell surface receptors displayed on target cells. The specific interactions that trigger infection are mediated by cross-molecular interactions between peptide motifs in capsid proteins that act as ligands, and target surface cell proteins that act as receptors for the virus. The multivalency of ligandreceptor binding based on the repetitive and regular architecture of viruses ensures a high degree of tissue and cell penetrability, and increases the likelihood of interaction. In parallel, an increasing number of peptides and protein domains have been described as tumor-homing peptides. They exhibit the ability to specifically bind cell-surface protein markers in CSCs or in more differentiated cells [21-23], with an important degree of discrimination between specific tumor types [24]. Alternatively, nonspecific cell-penetrating peptides have been 
engineered to be activated by local stimuli, such as low $\mathrm{pH}$, or by metaloproteases, which are present in tumor tissues [25].

All these categories of peptides are valuable tools in enabling the targeting of drugs to specific tumors or tumor cell sub-populations, provided they functionalize nano-sized vehicles in a multivalent and regular distribution. The 'artificial virus' concept was proposed to define any manmade biocompatible nanomaterial exhibiting virus-like characteristics and size, with the potential to be cell-targeted carriers in molecular therapies [26]. Metals, polymers, carbon nanotubes or lipids may be suitable for nanoparticle fabrication [27]. However, proteins are likely the most convenient materials for the construction of effective viral mimetics in therapy, since they are the ultimate supporters of biological functions and specificity in molecular interactions. Being fully biocompatible, proteins have been produced since decades in cell factories by cost-effective scalable bioproduction (or by chemical synthesis if short peptides), to be used, among other applications, as pharmaceuticals [28;29]. In this regard, the regulatory issues linked to the administration of proteins to humans have been already well addressed, and the number of endotoxin-free and generically recognized as safe (GRAS) microorganisms available for biological production of proteins is lately expanding [30]. In addition, precise protein engineering by conventional genetic approaches allows the modulation of their functional and structural properties in a very versatile way.

Furthermore, cost-effective large-scale production of difficult-to-express proteins and nanostructured protein materials is now becoming feasible due to accumulating advances in genetics and systems biotechnology $[31 ; 32]$ and the increasing availability of cell factories adapted to complex protein production 
challenges [30;33;34]. The multiple virus-like functions necessary for molecular transport and intracellular delivery can only be achieved by proteins, and different functions can be assumed by protein complexes of by the construction of single chain modular polypeptides that recruit diverse functional domains from independent origins [35]. The unique functional and structural plasticity of proteins is ideal for the generation of multifunctional vehicles adapted to the targeted transportation of specific drug types, including nucleic acids (in nonviral gene therapy) and chemicals (in chemotherapy). Although protein-based viral mimetics have great potential for use in cancer therapy [36], rapid development of therapeutic artificial viruses has been unfortunately impaired by still limited structural comprehension of protein-protein interactions and by the lack of universal tools to predict and engineer precise contacts between designed polypeptides. The ability to arrange building blocks in regular patterns to generate multivalent constructs of defined nanoscale size, is an unavoidable requirement for the de novo generation of virus-like assemblies. Although control over particle size has been more easily reached in the design of liposomes and related polymer-based vehicles, the issue is much more challenging in the case of protein vehicles. Some recent successes in the computing-assisted design of complex protein nanostructures [37;38] permit to envisage, however, the feasibility of tailoring multimeric protein nanomaterials.

\section{Emerging nanoarchitectonic principles, viral mimetics and antitumoral drug delivery}

In this context, protein science has benefited from multiple approaches to engineering protein self-assembly [36;39], which have resulted in the generation of a wide range of nanoparticles and nanostructured materials [40]. The most promising routes to reach functional protein nanoparticles include: exploitation of 
the amphiphillic character of peptides and proteins, the adaptation of natural oligorimerization domains and the manipulation of charge distribution to modulate electrostatic protein-protein interactions (Table 1). A fraction of these constructs tend to mimic viral features through the self-organization of multifunctional building blocks in virus-like assemblies, within the viral size range and with regular or filamentous morphologies (Figure 1). Among such constructs, those empowered with protein segments that bind cancer cell markers display specificity for cancer cells in vitro and reach tumor tissues in vivo, thus promoting a desired biodistribution map while avoiding renal filtration [41]. The repetitive nature of the building blocks in both spherical and filamentous nanoparticles allows for a multivalent display of cell ligands. The multivalent and regular ligand display in artificial viruses favours cell binding and endosomalmediated uptake, as is the case in natural viruses, e.g. human rhinovirus 14 particles, which bind to different molecules of the cell surface receptor ICAM-1 (Figure $1 \mathrm{H}$ ). When loaded with conventional anti-tumor drugs, drug stability is often enhanced and the specificity and efficacy of cell killing is dramatically improved in comparison to soluble free drugs (Table 1). Some multifunctional proteins of this kind have already entered clinical trials [42].

In a paradigmatic example of viral mimetics, multifunctional single chain proteins were developed based on the linear fusion of three main cassettes: an amino terminal cationic peptide, a core scaffold protein and a carboxy terminal polyhistidine [43]. Such an engineering scheme is extremely efficient in promoting the self-organization of the whole chimera under aqueous physiological conditions [41], as nanoparticles of regulatable size between 10 and $80 \mathrm{~nm}$ [44]. This is irrespective of the particular scaffold protein used as building block core, and the particular amino acid sequence of the amino 
terminal segment. These constructs are stable in vivo and escape renal filtration, exhibiting a high degree cellular penetrability both in cell culture and in vivo [41;45-47]. The regular disposition of the building blocks as planar toroid entities (Figure 1) [41] ensures a symmetric presentation of functional motifs on the particle surface. When the carboxy terminal region of the building block corresponds to a cancer relevant ligand, such as the tumor homing peptides T22 and A5 (which bind the cancer cell markers CXCR4 and CD44 respectively), high cell specificity has been achieved both in cell culture and in vivo [41;46;47]. T22empowered CXCR4-targeted protein nanoparticles penetrated CXCR4 ${ }^{+}$cells in both primary tumor and metastatic foci in colorectal cancer mice models $[46 ; 48]$. It is already possible to load artificial viruses with expressible DNA for gene delivery [48]. Coupling artificial viruses to anti-tumor compounds would be a logical next step.

\section{Concluding remarks and future perspectives.}

In summary, the versatility of protein engineering regarding structure and function offers unique opportunities for the construction of viral mimetics adapted to targeted drug delivery in molecular cancer therapies. Long-term experience in the biofabrication of enzymes and protein drugs ensures costeffective large-scale biofabrication under GMP and the overcoming of any regulatory constraint for clinical use. Surpassing other materials of common use in Nanotechnology, self-assembling peptides and proteins are exceptional building blocks that allow efficient design and fabrication of biocompatible artificial viruses for the treatment of cancer. These entities can then be tailored to overcome the current limitations of chemotherapy associated with poor effectiveness and toxicity, by promoting longer circulation time and enhancing selective delivery of the cargo drug into target cancer cells. The rapidly growing 
list of tumor-homing peptides and the refining of nano-architectonic protein engineering principles has already generated excitement for first-generation prototypes in the still nascent area of artificial virus design. Although these viral mimetics can be loaded with conventional chemical drugs or nucleic acids, the versatile nature of their protein building blocks makes them fully adaptable to any next generation passenger drug that might be incorporated into the clinical use in the future.

Acknowledgments. The authors acknowledge the financial support on the development of nano-therapeutics in cancer granted to E.V. (PI12/00327) and R.M. (PI12/01861) from FIS, to E.V. (TV32013-133930) and to R.M. and A.V. (TV32013-132031) from La Marató de TV3 (416/C/2013), to A.V. from MINECO (BIO2013-41019-P) and from the Centro de Investigación Biomédica en Red (CIBER) de Bioingeniería, Biomateriales y Nanomedicina (NANOPROTHER and NANOCOMETS projects), financed by the Instituto de Salud Carlos III with assistance from the European Regional Development Fund. U.U. received a fellowship grant from ISCIII. A.V. has been distinguished with an ICREA ACADEMIA Award.

Competing interests: UU, EV, NFM, AV, RM and MVC are cited as inventors in a patent application (EP11382005.4) covering the therapeutic use of the peptide T22. 
Legends

Figure 1. Diverse categories of drug-loadable protein-based artificial viruses resulting from the self-assembling of repetitive building blocks. (A): E2 proteinbased nanoparticles formed by 60 repetitive units and with an hydrodynamic size of around $33 \mathrm{~nm}$. Reproduced with permission from [49]. (B): Decameric, GFP-based 13 nm-nanoparticles organized in a star-shaped distribution, that display the efficient CXCR4 ligand T22. Reproduced with permission from [41]. (C): Modular, elastin-like polypeptide assembled in doxorubicin-containing nanoparticles of about $20 \mathrm{~nm}$ in diameter. Reproduced with permission from [50]. (D): Dodecahedral, $16 \mathrm{~nm}$-nanoparticles constructed by self-assembling modular peptides comprising several tandem architectonic domains. Reproduced with permission from [51]. (E): Nanoparticles of around $20 \mathrm{~nm}$ constructed by the trigonal-WTW modular protein, that comprises three tandem, tryptophane zipperforming peptides. Reproduced with permission from [52]. (F): Nanoparticles ranging 20-30 nm formed by branched amphiphilic peptides. Reproduced with permission from [53]. (G): Peptide amphiphile nanofibers encapsulating camptothecin. Reproduced with permission from [54]. (H): Cryo-Tem image reconstruction of the regular human rhinovirus 14 particles bound to different molecules of the cell surface receptor ICAM-1. Precise nanoparticle dimensions as well as the nature and properties of the building blocks can be found in Table 1 . Copyrights are from Macmillan Publishers Ltd (2009), Elsevier (2006, 2014), Royal Society of Chemistry (2011), John Wiley and Sons (1999) and American $\begin{array}{llll}\text { Chemical Society } & \text { 2014). }\end{array}$ 


\section{Box 1.Nanoparticle-baseddrugdeliveryincancer}

Nanotechnology can improve cancer therapy by manipulating the functional components of drug vehicles and their architecture and size to ensure adequate biodistribution and accumulation in tumor (Figure I). Drug-protein conjugation avoids renal filtration by enlarging the drug size over $7 \mathrm{~nm}$ and reduces liver clearance, especially when blocking phagocytosis by the MPS (for instance by PEGylation). These effects determine a long circulation time for the nanoconjugate in the bloodstream that improves tumor penetration. In addition, active targeting to tumor cells or cancer stem cells (e.g. CXCR4 ${ }^{+}$cells) promotes tumor accumulation and improves the antitumoral effect. This approach allows the targeting of cell surface receptors that are overexpressed in tumor cells by designing nanoconjugates that incorporate a specific ligand. Specific and multivalent binding would be triggering receptor-mediated endocytosis and drug release in the cytosol. This strategy promises to achieve high antitumor effect, while low drug accumulation and reduced adverse effects in normal tissues as compared to the administration of the free drug or plain drug-protein conjugates.

Figure 1. Schematic diagram showing how cell-targeted, nanoscale viral mimetics used as drug carriers improve drug biodistribution and efficacy in cancer therapy. 


\section{Glossarybox}

Active targeting: Directioning of ligand-driven nanoparticles to tumor cell types displaying specific membrane receptors used as targets

Biodistribution: Map of where compounds or drugs occur in the body of an animal or human being upon administration

Blood circulation time: Time that a nanoconjugate remains detectable in the bloodstream

Cancer stem cells: Cells responsible for maintaining the tumor due to their capacity for self-renewal and differentiation

Cell penetrating peptides: Peptides able to translocate the cell membrane and to allow the internalization of associated compounds

EPR effect: Enhanced permeability and retention of nanoparticles in tumor tissue because of their irregularly fenestrated vessels and impaired lymphatic drainage

GRAS: A distinctive label given by the American Food and Drug Administration to substances of microorganism to design that their addition to food is safe Hepatic clearance: Inactivation of a drug through hepatic metabolism MPS: Mononuclear phagocytic system responsible for phagocytosis and degradation of particular nanoparticle types

Nanoconjugate: Therapeutic molecule composed of a drug covalently bound to a nanoparticle

PEGylation: Attaching polyethylene-glycol molecules to nanoparticles to alter their physicochemical properties

Passive targeting: Directioning of nanoparticles to tumors by virtue of the EPR effect

RGD: Arginine, glycine, and aspartic acid tripeptide frequently used in drug delivery and tissue engineering because of its ability to bind certain cell surface integrins

Renal clearance: Elimination from the body of drugs smaller than $7 \mathrm{~nm}$, by filtration through the kidney

Trancytosis: Endosomal transport of molecules from one side of the cell to the opposite side

Tumor-homing peptides: Peptides that show high affinity for proteins overexpressed at the surface of cancer cells and that are used as agents for drug targeting 
Table 1. Diversity of engineering strategies to control protein-protein contacts in proteinbased viral mimetics, illustrated by representative examples.

\begin{tabular}{|c|c|c|c|c|}
\hline $\begin{array}{lr}\text { Building } & \text { block } \\
\text { structure or self- } \\
\text { assembling principle }\end{array}$ & $\begin{array}{l}\text { Morphology } \\
\text { and size }\end{array}$ & Example cargo & Target & References \\
\hline Peptide amphiphiles & $\begin{array}{l}\text { Fibrils; } 100-900 \\
\mathrm{~nm} \text { in length. }\end{array}$ & $\begin{array}{l}\text { Cytotoxic peptides } \\
\text { (KLAK) }\end{array}$ & Transformed cells & {$[55]$} \\
\hline Peptide amphiphiles & $\begin{array}{l}\text { Nanofibers; } \\
\text { unidentified } \\
\text { length }\end{array}$ & Camptothecin & $\begin{array}{lr}\text { Human } & \text { breast } \\
\text { cancer } & \text { in } \\
\text { orthotopic } & \text { mice } \\
\text { models } & \end{array}$ & [54] \\
\hline $\begin{array}{l}\text { Branched peptide } \\
\text { amphiphiles }\end{array}$ & $\begin{array}{l}\text { Capsular } \\
\text { spheres; } 10-20 \\
\mathrm{~nm}\end{array}$ & Radionuclides & $\begin{array}{l}\text { Not defined. } \\
\text { Potential in cancer } \\
\text { therapy suggested }\end{array}$ & [53] \\
\hline $\begin{array}{l}\text { Branched } \\
\text { peptides }\end{array}$ & $\begin{array}{l}\text { Capsular } \\
\text { spheres; } 20-500 \\
\mathrm{~nm}\end{array}$ & Model eosin Y dye & Not defined & {$[56]$} \\
\hline $\begin{array}{l}\text { Self-assembling } \\
\text { peptides fused to PEG }\end{array}$ & $\begin{array}{l}\text { Planar } \\
\text { A日Dofibars; } 50 \text { q } \\
\text { length. }\end{array}$ & None described & $\begin{array}{l}\text { Glioblastoma } \\
\text { mice models }\end{array}$ & [57] \\
\hline $\begin{array}{l}\text { RGD-containing self- } \\
\text { assembling peptide }\end{array}$ & $\begin{array}{l}\text { Single layer } \\
\text { nanofibers; } \\
\text { unidentified } \\
\text { length }\end{array}$ & Curcumin & $\begin{array}{l}\text { Hepatic cancer in } \\
\text { xenograft mice } \\
\text { models }\end{array}$ & [58] \\
\hline $\begin{array}{l}\text { Cationic end-terminal } \\
\text { domains in modular } \\
\text { proteins }\end{array}$ & $\begin{array}{l}\text { Regular toroids; } \\
15-30 \mathrm{~nm}\end{array}$ & DNA & $\begin{array}{lr}\text { Human } & \text { colorectal } \\
\text { cancer } & \text { in } \\
\text { orthotopic } & \text { mice } \\
\text { models } & \end{array}$ & {$[41 ; 46 ; 48]$} \\
\hline $\begin{array}{l}\text { Engineered E2 subunit } \\
\text { of } \\
\text { dehydrogenase enzymate } \\
\text { complex }\end{array}$ & $\begin{array}{l}\text { Hollow } \\
\text { dodecahedral } \\
\text { nanoparticles; } \\
25 \mathrm{~nm}\end{array}$ & Doxorubicin & $\begin{array}{l}\text { Human breast } \\
\text { cancer cells }\end{array}$ & {$[49 ; 59]$} \\
\hline $\begin{array}{l}\text { Trigonal tryptophan } \\
\text { zipper }\end{array}$ & $\begin{array}{l}\text { Nanospheres; } \\
20 \mathrm{~nm})\end{array}$ & None described & Not defined & [52] \\
\hline $\begin{array}{l}\text { Coiled } \\
\text { oligomerization } \\
\text { domains }\end{array}$ & $\begin{array}{l}\text { Polyhedral } \\
\text { nanoparticles; } \\
16 \mathrm{~nm}\end{array}$ & None described & Not defined & [51] \\
\hline $\begin{array}{l}\text { Cys-rich peptides fused } \\
\text { to an elastin-like protein }\end{array}$ & $\begin{array}{l}\text { Nanoparticles; } \\
20 \mathrm{~nm}\end{array}$ & Doxorubicin & $\begin{array}{l}\text { Not defined. } \\
\text { Tested in mice } \\
\text { tumour models }\end{array}$ & {$[50]$} \\
\hline Engineered silk proteins & $\begin{array}{l}\text { Spheres; } \\
\mathrm{nm}\end{array}$ & Doxorubicin & $\begin{array}{l}\text { Her2- } \\
\text { overexpressing } \\
\text { cultured cells }\end{array}$ & {$[60]$} \\
\hline $\begin{array}{l}\text { Human serum albumin } \\
\text { after denaturation and } \\
\text { further solubilization }\end{array}$ & $\begin{array}{l}\text { Nanoparticles; } \\
120 \mathrm{~nm}\end{array}$ & Paclitaxel & $\begin{array}{l}\text { Not defined. } \\
\text { Tested in H22 } \\
\text { tumor-bearing } \\
\text { mice }\end{array}$ & [61] \\
\hline $\begin{array}{l}\text { Self-assembling } \\
\text { apotranterrin } \\
\text { lactoferrin }\end{array}$ & $\begin{array}{l}\text { Nanoparticles; } \\
140 \mathrm{~nm} \text { and } \\
260 \mathrm{~nm} \\
\text { respectively }\end{array}$ & Carboplatin & $\begin{array}{l}\text { Retinoblastoma } \\
\text { cells }\end{array}$ & [62] \\
\hline Folate-conjugated & Nanospheres & Organic & Several tumor cell & [63] \\
\hline
\end{tabular}


bovine serum albumin $255 \mathrm{~nm}-470 \mathrm{~nm}$ selenocompound lines

PEG: Polyethylene glycol

RGD: Arg-Gly-Asp motif

References

[1] The top 10 causes of death. http://www.who.int/mediacentre/factsheets/fs310/en/ Who Fact sheet N³10. 2014.

[2] R. Siegel, J. Ma, Z. Zou, A. Jemal, Cancer statistics, 2014. CA Cancer J.Clin. 64 (2014) 9-29.

[3] S. Dasari, P.B. Tchounwou, Cisplatin in cancer therapy: molecular mechanisms of action. Eur.J.Pharmacol. 740 (2014) 364-378.

[4] Skeel RT, Khleif SN Handbook of Cancer Chemotherapy, 2011.

[5] G. Damia, S. Garattini, The pharmacological point of view of resistance to therapy in tumors. Cancer Treat.Rev. 40 (2014) 909-916.

[6] Akhdar H, Legendre C, Aninat C, More F Anticancer Drug Metabolism: Chemotherapy Resistance and New Therapeutic Approaches, Topics on Drug Metabolism, InTech, 2012.

[7] B. Feng, J.L. LaPerle, G. Chang, M.V. Varma, Renal clearance in drug discovery and development: molecular descriptors, drug transporters and disease state. Expert.Opin.Drug Metab Toxicol. 6 (2010) 939-952.

[8] F. Danhier, O. Feron, V. Preat, To exploit the tumor microenvironment: Passive and active tumor targeting of nanocarriers for anti-cancer drug delivery. J.Control Release 148 (2010) 135-146.

[9] U. Prabhakar, H. Maeda, R.K. Jain, E.M. Sevick-Muraca, W. Zamboni, O.C. Farokhzad, S.T. Barry, A. Gabizon, P. Grodzinski, D.C. Blakey, Challenges and key considerations of the enhanced permeability and retention effect for nanomedicine drug delivery in oncology. Cancer Res. 73 (2013) 24122417.

[10] A. Schroeder, D.A. Heller, M.M. Winslow, J.E. Dahlman, G.W. Pratt, R. Langer, T. Jacks, D.G. Anderson, Treating metastatic cancer with nanotechnology. Nat.Rev.Cancer 12 (2012) 39-50.

[11] C.M. Dawidczyk, C. Kim, J.H. Park, L.M. Russell, K.H. Lee, M.G. Pomper, P.C. Searson, State-of-the-art in design rules for drug delivery platforms: lessons learned from FDA-approved nanomedicines. J.Control Release 187 (2014) 133-144.

[12] Y. Malam, M. Loizidou, A.M. Seifalian, Liposomes and nanoparticles: 
nanosized vehicles for drug delivery in cancer. Trends Pharmacol.Sci. 30 (2009) 592-599.

[13] F. Alexis, E. Pridgen, L.K. Molnar, O.C. Farokhzad, Factors affecting the clearance and biodistribution of polymeric nanoparticles. Mol.Pharm. 5 (2008) 505-515.

[14] C. Heneweer, J.P. Holland, V. Divilov, S. Carlin, J.S. Lewis, Magnitude of enhanced permeability and retention effect in tumors with different phenotypes: 89Zr-albumin as a model system. J.Nucl.Med. 52 (2011) 625633.

[15] R. Duncan, R. Gaspar, Nanomedicine(s) under the microscope. Mol.Pharm. 8 (2011) 2101-2141.

[16] A. Neesse, K.K. Frese, D.S. Chan, T.E. Bapiro, W.J. Howat, F.M. Richards, V. Ellenrieder, D.I. Jodrell, D.A. Tuveson, SPARC independent drug delivery and antitumour effects of nab-paclitaxel in genetically engineered mice. Gut 63 (2014) 974-983.

[17] A. Neesse, P. Michl, D.A. Tuveson, V. Ellenrieder, nab-Paclitaxel: novel clinical and experimental evidence in pancreatic cancer. Z.Gastroenterol. 52 (2014) 360-366.

[18] M. Huang, A. Shen, J. Ding, M. Geng, Molecularly targeted cancer therapy: some lessons from the past decade. Trends Pharmacol.Sci. 35 (2014) 4150 .

[19] A. Mantovani, B. Savino, M. Locati, L. Zammataro, P. Allavena, R. Bonecchi, The chemokine system in cancer biology and therapy. Cytokine Growth Factor Rev. 21 (2010) 27-39.

[20] A.K. Singh, R.K. Arya, A.K. Trivedi, S. Sanyal, R. Baral, O. Dormond, D.M. Briscoe, D. Datta, Chemokine receptor trio: CXCR3, CXCR4 and CXCR7 crosstalk via CXCL11 and CXCL12. Cytokine Growth Factor Rev. 24 (2013) 41-49.

[21] P. Kapoor, H. Singh, A. Gautam, K. Chaudhary, R. Kumar, G.P. Raghava, TumorHoPe: a database of tumor homing peptides. PLoS.One. 7 (2012) e35187.

[22] X.X. Zhang, H.S. Eden, X. Chen, Peptides in cancer nanomedicine: drug carriers, targeting ligands and protease substrates. J.Control Release 159 (2012) 2-13.

[23] A. Gautam, P. Kapoor, K. Chaudhary, R. Kumar, G.P. Raghava, Tumor homing peptides as molecular probes for cancer therapeutics, diagnostics and theranostics. Curr.Med.Chem. 21 (2014) 2367-2391.

[24] M.J. McGuire, B.P. Gray, S. Li, D. Cupka, L.A. Byers, L. Wu, S. Rezaie, Y.H. Liu, N. Pattisapu, J. Issac, T. Oyama, L. Diao, J.V. Heymach, X.J. Xie, J.D. Minna, K.C. Brown, Identification and characterization of a suite of tumor targeting peptides for non-small cell lung cancer. Sci.Rep. 4 (2014) 4480.

[25] E. Vives, J. Schmidt, A. Pelegrin, Cell-penetrating and cell-targeting 
peptides in drug delivery. Biochim.Biophys.Acta 1786 (2008) 126-138.

[26] E. Mastrobattista, M.A. van der Aa, W.E. Hennink, D.J. Crommelin, Artificial viruses: a nanotechnological approach to gene delivery. Nat.Rev.Drug Discov. 5 (2006) 115-121.

[27] Villaverde A Nanoparticles in translational science and medicine, Academic Press (Elsevier), London, 2011.

[28] N. Ferrer-Miralles, J. Domingo-Espin, J.L. Corchero, E. Vazquez, A. Villaverde, Microbial factories for recombinant pharmaceuticals. Microb.Cell Fact. 8 (2009) 17.

[29] N.A. Baeshen, M.N. Baeshen, A. Sheikh, R.S. Bora, M. Ahmed, H.I. Ramadan, K. Saini, E.M. Redwan, Cell factories for insulin production. Microb.Cell Fact. 13 (2014) 141.

[30] N. Ferrer-Miralles, A. Villaverde, Bacterial cell factories for recombinant protein production; expanding the catalogue. Microb.Cell Fact. 12 (2013) 113.

[31] S. Mahalik, A.K. Sharma, K.J. Mukherjee, Genome engineering for improved recombinant protein expression in Escherichia coli. Microb.Cell Fact. 13 (2014) 177.

[32] M.A. de, Recombinant polypeptide production in E. coli: towards a rational approach to improve the yields of functional proteins. Microb.Cell Fact. 12 (2013) 101.

[33] R. Chen, Bacterial expression systems for recombinant protein production: E. coli and beyond. Biotechnol.Adv. 30 (2012) 1102-1107.

[34] J.L. Corchero, B. Gasser, D. Resina, W. Smith, E. Parrilli, F. Vazquez, I. Abasolo, M. Giuliani, J. Jantti, P. Ferrer, M. Saloheimo, D. Mattanovich, Schwartz S Jr, L. Tutino, A. Villaverde, Unconventional microbial systems for the cost-efficient production of high-quality protein therapeutics. Biotechnol.Adv. 31 (2013) 140-153.

[35] A. Aris, A. Villaverde, Modular protein engineering for non-viral gene therapy. Trends Biotechnol. 22 (2004) 371-377.

[36] E. Vazquez, N. Ferrer-Miralles, R. Mangues, J.L. Corchero, Schwartz S Jr, A. Villaverde, Modular protein engineering in emerging cancer therapies. Curr.Pharm.Des 15 (2009) 893-916.

[37] N.P. King, J.B. Bale, W. Sheffler, D.E. McNamara, S. Gonen, T. Gonen, T.O. Yeates, D. Baker, Accurate design of co-assembling multi-component protein nanomaterials. Nature 510 (2014) 103-108.

[38] N.P. King, W. Sheffler, M.R. Sawaya, B.S. Vollmar, J.P. Sumida, I. Andre, T. Gonen, T.O. Yeates, D. Baker, Computational design of self-assembling protein nanomaterials with atomic level accuracy. Science 336 (2012) 1171-1174.

[39] E. Vazquez, A. Villaverde, Engineering building blocks for self-assembling 
protein nanoparticles. Microb.Cell Fact. 9 (2010) 101.

[40] Neus Ferrer-Miralles, Escarlata Rodriguez-Carmona, Jose Luis Corchero, Elena Garcia-Fruitos, Esther Vazquez, Antonio Villaverde, Engineering protein self-assembling in protein-based nanomedicines for drug delivery and gene therapy. Crit Rev.Biotechnol in press (2013).

[41] M.V. Cespedes, U. Unzueta, W. Tatkiewicz, A. Sanchez-Chardi, O. ConchilloSole, P. Alamo, Z. Xu, I. Casanova, J.L. Corchero, M. Pesarrodona, J. Cedano, X. Daura, I. Ratera, J. Veciana, N. Ferrer-Miralles, E. Vazquez, A. Villaverde, R. Mangues, In Vivo Architectonic Stability of Fully de Novo Designed Protein-Only Nanoparticles. ACS Nano. 8 (2014) 4166-4176.

[42] A.A. Kaspar, J.M. Reichert, Future directions for peptide therapeutics development. Drug Discov.Today 18 (2013) 807-817.

[43] E. Vazquez, M. Roldan, C. Diez-Gil, U. Unzueta, J. Domingo-Espin, J. Cedano, O. Conchillo, I. Ratera, J. Veciana, X. Daura, N. Ferrer-Miralles, A. Villaverde, Protein nanodisk assembling and intracellular trafficking powered by an arginine-rich (R9) peptide. Nanomedicine.(Lond) 5 (2010) 259-268.

[44] U. Unzueta, N. Ferrer-Miralles, J. Cedano, X. Zikung, M. Pesarrodona, P. Saccardo, E. Garcia-Fruitos, J. Domingo-Espin, P. Kumar, K.C. Gupta, R. Mangues, A. Villaverde, E. Vazquez, Non-amyloidogenic peptide tags for the regulatable self-assembling of protein-only nanoparticles. Biomaterials 33 (2012) 8714-8722.

[45] E. Vazquez, R. Cubarsi, U. Unzueta, M. Roldan, J. Domingo-Espin, N. FerrerMiralles, A. Villaverde, Internalization and kinetics of nuclear migration of protein-only, arginine-rich nanoparticles. Biomaterials 31 (2010) 93339339.

[46] U. Unzueta, M.V. Cespedes, N. Ferrer-Miralles, I. Casanova, Cedano JA, Corchero JL, J. Domingo-Espin, Villaverde A, R. Mangues, Vazquez E, Intracellular $\mathrm{CXCR}^{+}$cell targeting with T22-empowered protein-only nanoparticles. Int.J. Nanomedicine 7 (2012) 4533-4544.

[47] M. Pesarrodona, N. Ferrer-Miralles, U. Unzueta, P. Gener, W. Tatkiewicz, I. Abasolo, I. Ratera, J. Veciana, S.S. Jr, A. Villaverde, E. Vazquez, Intracellular targeting of CD44 cells with self-assembling, protein only nanoparticles. Int.J.Pharm. 473 (2014) 286-295.

[48] U. Unzueta, P. Saccardo, J. Domingo-Espin, J. Cedano, O. Conchillo-Sole, E. Garcia-Fruitos, M.V. Cespedes, J.L. Corchero, X. Daura, R. Mangues, N. Ferrer-Miralles, A. Villaverde, E. Vazquez, Sheltering DNA in self-organizing, protein-only nano-shells as artificial viruses for gene delivery. Nanomedicine. 10 (2014) 535-541.

[49] D. Ren, M. Dalmau, A. Randall, M.M. Shindel, P. Baldi, S.W. Wang, Biomimetic Design of Protein Nanomaterials for Hydrophobic Molecular Transport. Adv.Funct.Mater. 22 (2012) 3170-3180.

[50] J.A. MacKay, M. Chen, J.R. McDaniel, W. Liu, A.J. Simnick, A. Chilkoti, Selfassembling chimeric polypeptide-doxorubicin conjugate nanoparticles that 
abolish tumours after a single injection. Nat.Mater. 8 (2009) 993-999.

[51] S. Raman, G. Machaidze, A. Lustig, U. Aebi, P. Burkhard, Structure-based design of peptides that self-assemble into regular polyhedral nanoparticles. Nanomedicine. 2 (2006) 95-102.

[52] K. Matsuura, H. Hayashi, K. Murasato, N. Kimizuka, Trigonal tryptophane zipper as a novel building block for pH-responsive peptide nanoassemblies. Chem.Commun.(Camb.) 47 (2011) 265-267.

[53] P. Sukthankar, L.A. Avila, S.K. Whitaker, T. Iwamoto, A. Morgenstern, C. Apostolidis, K. Liu, R.P. Hanzlik, E. Dadachova, J.M. Tomich, Branched amphiphilic peptide capsules: cellular uptake and retention of encapsulated solutes. Biochim.Biophys.Acta 1838 (2014) 2296-2305.

[54] S. Soukasene, D.J. Toft, T.J. Moyer, H. Lu, H.K. Lee, S.M. Standley, V.L. Cryns, S.I. Stupp, Antitumor activity of peptide amphiphile nanofiberencapsulated camptothecin. ACS Nano. 5 (2011) 9113-9121.

[55] S.M. Standley, D.J. Toft, H. Cheng, S. Soukasene, J. Chen, S.M. Raja, V. Band, H. Band, V.L. Cryns, S.I. Stupp, Induction of cancer cell death by selfassembling nanostructures incorporating a cytotoxic peptide. Cancer Res. 70 (2010) 3020-3026.

[56] P. Sukthankar, S. Gudlur, L.A. Avila, S.K. Whitaker, B.B. Katz, Y. Hiromasa, J. Gao, P. Thapa, D. Moore, T. Iwamoto, J. Chen, J.M. Tomich, Branched oligopeptides form nanocapsules with lipid vesicle characteristics. Langmuir 29 (2013) 14648-14654.

[57] A. Wagh, J. Singh, S. Qian, B. Law, A short circulating peptide nanofiber as a carrier for tumoral delivery. Nanomedicine. 9 (2013) 449-457.

[58] J. Liu, J. Liu, H. Xu, Y. Zhang, L. Chu, Q. Liu, N. Song, C. Yang, Novel tumortargeting, self-assembling peptide nanofiber as a carrier for effective curcumin delivery. Int.J. Nanomedicine. 9 (2014) 197-207.

[59] D. Ren, F. Kratz, S.W. Wang, Protein nanocapsules containing doxorubicin as a pH-responsive delivery system. Small 7 (2011) 1051-1060.

[60] A. Florczak, A. Mackiewicz, H. Dams-Kozlowska, Functionalized spider silk spheres as drug carriers for targeted cancer therapy. Biomacromolecules. 15 (2014) 2971-2981.

[61] D. Ding, X. Tang, X. Cao, J. Wu, A. Yuan, Q. Qiao, J. Pan, Y. Hu, Novel selfassembly endows human serum albumin nanoparticles with an enhanced antitumor efficacy. AAPS.PharmSciTech. 15 (2014) 213-222.

[62] F. Ahmed, M.J. Ali, A.K. Kondapi, Carboplatin loaded protein nanoparticles exhibit improve anti-proliferative activity in retinoblastoma cells. Int J.Biol.Macromol. 70 (2014) 572-582.

[63] Y. Huang, Y. Luo, W. Zheng, T. Chen, Rational Design of Cancer-Targeted BSA Protein Nanoparticles as Radiosensitizer to Overcome Cancer Radioresistance. ACS Appl.Mater.Interfaces 6 (2014) 19217-19228. 